Available online at http://jurnal.goretanpena.com/index.php/JSSR

\title{
RANCANG BANGUN SISTEM PENDUKUNG KEPUTUSAN PENILAIAN KESEHATAN TANAH PADA TANAMAN JAGUNG DENGAN METODE SIMPLE ADDITIVE WEIGHTING BERBASIS DESKTOP
}

\author{
Ricky Ramadhan Harahap ${ }^{1}$, Sri Wahyuni ${ }^{2}$, Dinda Rizki Putri ${ }^{3}$ \\ Universitas Pembangunan Panca Budi, Medan \\ e-mail: rickram0704@gmail.com ${ }^{1}$, yuke@dosen.pancabudi.ac.id ${ }^{2}$, \\ dindarizki793@gmail.com ${ }^{3}$
}

\begin{abstract}
Soil is a medium for plant growth. Soil is also a habitat for various organisms that live in it. Between plants and organisms in the soil there is a very close interdependence relationship. Therefore the population of soil organisms is determined by the quality of the vegetation on it. On the other hand, the activity of organisms in the soil will also affect plant growth which will ultimately determine the productivity of the land where they live (Widyati, 2013). Soil components consisting of solids, water and air are the main natural resources that greatly affect life. Soil has the main function as a place to grow and produce plants. The ability of soil as a growing medium will be optimal if it is supported by good physical, chemical and biological properties, usually indicating the level of soil fertility. Comprehensive soil health assessment can be carried out based on soil health indicators consisting of soil physical, chemical and biological properties. However, there is no fixed standard for assessing soil health, and not all communities, especially agricultural land managers, know and understand soil health indicators. The many indicators in soil health assessment can also make it difficult for researchers to assess soil health in an area. For this reason, the author will create an application system that can conduct an assessment of the soil to determine whether the soil to be used is in good condition or not. The application that will be made by the author uses visual studio 2012 software with visual basic programming language and mysql database to produce desktop-based applications. The system is made as easy as possible to make it easier for landowners to use and understand to assess soil health in maize crops.stem using the waterfall method.
\end{abstract}

Keywords: Corn, SAW, Visual Basic, Desktop.

Abstrak: Tanah merupakan media tempat tumbuhnya tanaman. Tanah juga merupakan
habitat bagi berbagai organisme yang hidup di dalamnya. Antara tanaman dengan
organisme dalam tanah terjadi suatu hubungan saling ketergantungan yang sangat erat.
Oleh karena itu populasi organisme tanah ditentukan oleh kualitas vegetasi di atasnya.
Sebaliknya, aktivitas organisme dalam tanah juga akan mempengaruhi pertumbuhan
tanaman yang pada akhirnya akan menentukan produktivitas lahan tempat mereka hidup
(Widyati, 2013). Komponen tanah yang terdiri dari bahan padatan, air dan udara
merupakan sumberdaya alam utama yang sangat memengaruhi kehidupan. Tanah
mempunyai fungsi utama sebagai tempat tumbuh dan berproduksi tanaman. Kemampuan
tanah sebagai media tumbuh akan optimal jika didukung oleh sifat fisika, kimia dan
biologi yang baik, biasanya menunjukkan tingkat kesuburan tanah.Penilaian kesehatan
tanah secara komprehensif dapat dilakukan berdasarkan indikator-indikator kesehatan
tanah yang terdiri dari sifat fisik, kimia, dan biologi tanah. Namun belum terdapat standar
tetap dalam menilai kesehatan tanah, dan belum semua masyarakat khususnya pengelola
lahan pertanian mengetahui dan memahami indikator kesehatan tanah. Banyaknya
indikator dalam penilaian kesehatan tanah juga dapat menyulitkan peneliti dalam menilai
kesehatan tanah di suatu daerah. Untuk itu penullis akan membuat suatu sistem aplikasi 
Available online at http://jurnal.goretanpena.com/index.php/JSSR

yang dapat melakukan penilian terhadap tanah untuk diketahui apakah tanah yang akan digunakan tersebut dalam kondisi baik atau tidaknya. Aplikasi yang akan dibuat penulis menggunakan software visual studio 2012 dengan bahasa pemrograman visual basic dan database mysql untuk menghasilkan aplikasi yang berbasis desktop. Sistem dibuat semudah mungkin agar dapat lebih mudah digunakan dan dipahami oleh pemilik tanah untuk menilai Kesehatan tanah pada tanaman jagung.

Kata kunci: Jagung, SAW, Visual Basic, Desktop.

\section{PENDAHULUAN}

Tanah merupakan media tempat tumbuhnya tanaman. Tanah juga merupakan habitat bagi berbagai organisme yang hidup di dalamnya. Antara tanaman dengan organisme dalam tanah terjadi suatu hubungan saling ketergantungan yang sangat erat. Oleh karena itu populasi organisme tanah ditentukan oleh kualitas vegetasi di atasnya. Sebaliknya, aktivitas organisme dalam tanah juga akan mempengaruhi pertumbuhan tanaman yang pada akhirnya akan menentukan produktivitas lahan tempat mereka hidup (Widyati, 2013). Komponen tanah yang terdiri dari bahan padatan, air dan udara merupakan sumberdaya alam utama yang sangat memengaruhi kehidupan. Tanah mempunyai fungsi utama sebagai tempat tumbuh dan berproduksi tanaman. Kemampuan tanah sebagai media tumbuh akan optimal jika didukung oleh sifat fisika, kimia dan biologi yang baik, biasanya menunjukkan tingkat kesuburan tanah (Juarti, 2016).

Penilaian kesehatan tanah dalam pengelolaan lahan pertanian merupakan hal yang dibutuhkan untuk mengukur dan memantau status kesehatan tanah, yang bertujuan untuk mengetahui apakah tanah yang sedang atau akan digunakan di suatu daerah dalam kondisi sehat dan dapat menjalankan fungsinya dengan baik. Hasil penilaian kesehatan tanah juga dapat digunakan sebagai acuan bagi pengelola lahan pertanian dalam membuat target perencanaan dan penerapan sistem untuk mempraktikan pengelolaan kesehatan tanah dengan mengurangi kendala yang teridentifikasi. Selain itu dengan diketahuinya status kesehatan tanah pada suatu lahan, dapat mendorong pengelolalahan agar lebih baik dalam melakukan pencarian lahan pertanian, atau untuk mengelola lahan pertanian berkelanjutan secara regeneratif supaya dapat menjaga produktivitas tanah serta produksi pertanian dalam jangka panjang. Penilaian kesehatan tanah secara komprehensif dapat dilakukan berdasarkan indikator-indikator kesehatan tanah yang terdiri dari sifat fisik, kimia, dan biologi tanah. Namun belum terdapat standar tetap dalam menilai kesehatan tanah, dan belum semua masyarakat khususnya pengelola lahan pertanian mengetahui dan memahami indikator kesehatan tanah. Banyaknya indikator dalam penilaian kesehatan tanah juga dapat menyulitkan peneliti dalam menilai kesehatan tanah di suatu daerah.

Penelitian terdahulu adalah upaya peneliti untuk mencari perbandingan dan selanjutnya untuk menemukan inspirasi baru untuk penelitian selanjutnya di samping itu kajian terdahulu membantu penelitian dalam memposisikan penelitian serta menunjukkan orsinalitas dari penelitian. Peneliti mencantumkan berbagai hasil penelitian terdahulu yang terkait dengan penelitian yang hendak dilakukan. Kajian yang mempunyai relasi atau keterkaitan dengan kajian ini antara lain:

1. Saputra yang berjudul Sistem Pendukung Keputusan Pemilihan Kondisi Tanah Terbaik Untuk Perkebunan Di Desa Keputran Dengan Metode AHP. Yang mendeskripsikan dalam menentukan kondisi tanah terbaik untuk 
Available online at http://jurnal.goretanpena.com/index.php/JSSR

perkebunan digunakan beberapa kriteria diantaranya adalah Unsur Organik, Mineral, $\mathrm{CO} 2$ dan Air dan Letak.

2. Agus, dkk yang berjudul Pemetaan Zona Nilai Tanah Mengunakan Metode Analitical Heirarchy Process (AHP). Yang membicarakan tentang zona disekitar jalan arteri mempunyai nilai tanah tinggi karena jalan arteri merupakan factor penentu nilai tanah yang paling berpengaruh. Semakin tinggi bobot suatu zona yang diperoleh dari analisis spasial factor penentu nilai tanah maka semakin tinggi nilai tanah tersebut.

Adapun permasalahan yang dihadapi dalam membangun sistem pendukung keputusan penilaian kesuburan tanah ini adalah :

1. Apa saja faktor yang dibutuhkan untuk mengetahui kualitas tanah?

2. Seberapa jauh masyarakat dalam penilaian kesehatan tanah yang baik?

3. Bagaimana merancang sistem pendukung keputusan dengan menggunakan metode Simple Additive Weighting (SAW) dengan menggunkan bahasa program Visual Basic yang digunakan sebagai pendukung keputusan untuk menentukan kesehatan tanah?

Dalam sistem membangun sistem pendukung keputusan penilaian kesuburan tanah ini, penulis membatasi masalah sebagai berikut :

1. Aplikasi hanya dapat dijalankan berbasis komputer.

2. Sistem yang dibangun hanya untuk mengetahui kualitas tanah.

3. Metode yang digunakan Simple Additive Weighting (SAW).

4. Bahasa program yang digunakan adalah visual basic dengan menggunakan software visual studio 2012.

5. Database yang digunakan adalah MySQL dengan menggunakan software XAMPP.

Tujuan yang ingin dicapai penulis dalam sistem pendukung keputusan penilaian kesuburan tanah ini adalah :
1. Membuat suatu sistem aplikasi penilian tanah untuk dapat digunakan oleh semua orang.

2. Membantu dan memudahkan masyarakat dalam mengolah lahan.

3. Agar menambah pengetahuan dan wawasan penulis dalam merancang sistem penilaian kesehatan tanah.

Merancang aplikasi sistem

pendukung keputusan penilaian kesuburan tanah ini diharapkan bisa memberi manfaat bagi masyarakat antara lain:

1. Untuk menghasilkan suatu sistem pendukung keputusan penilaian kesehatan tanah pada tanaman jagung dengan metode Simple Additive Weighting berbasis Desktop

2. Untuk dapat mengetahui kualitas tanah dengan mudah menggunakan aplikasi.

3. Mempermudah pengguna sebagai acuan bagi pengelola lahan pertanian dalam membuat target perencanaan dan penerapannya.

4. Untuk menyediakan sebuah informasi, membimbing, memberikan prediksi serta mengarahkan kepada masyarakat agar dapat melakukan pengambilan keputusan dengan lebih tepat dan baik.

\section{METODE}

Metode pengumpulan data yang digunakan dalam penelitian ini adalah metode deskriptif. Adapun teknik pengumpulan data dilakukan dengan cara sebagai berikut:

1. Masalah dilakukan dalam pengamatan pada banyaknya masyarakat yang belum mengetahui kesehatan tanah untuk menanam tanaman jagung.

2. Pengumpulan data dengan menggunakan atau mengumpulkan sumber-sumber tertulis, dengan cara membaca, mempelajari dan mencatat hal-hal penting yang berhubungan dengan masalah yang sedang dibahas guna memperoleh gambaran secara teoritis. 
Available online at http://jurnal.goretanpena.com/index.php/JSSR

\section{Metode Pengembangan \\ Perangkat Lunak \\ Metodelogi yang digunakan untuk membangun sistem ini adalah Model Waterfall. Model ini terdiri dari beberapa tahapan, yaitu: System Engineering, Analysis, Design, Coding, Testing dan Maintenance. \\ Paradigma Waterfall dapat dilihat pada gambar berikut:

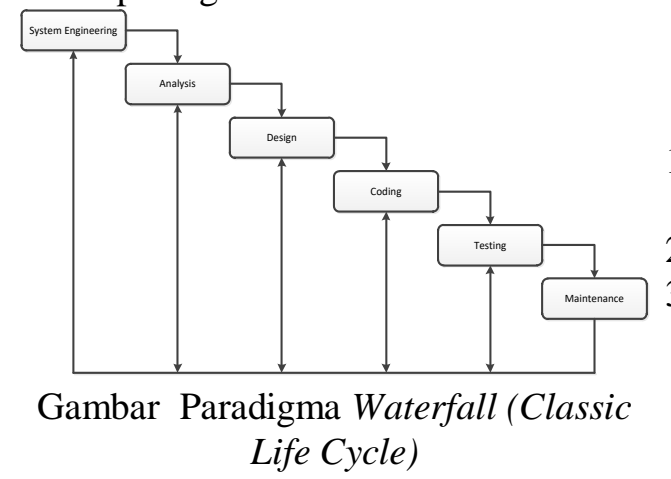

\section{HASIL DAN PEMBAHASAN}

Dalam perancangan aplikasi penilaian kesehatan tanah pada tanaman jagung ini, penulis menggunakan program aplikasi yang berbasis desktop dengan visual basic sebagai bahasa pemrogramannya. Program yang penulis buat cukup sederhana dan mudah untuk digunakan karena pengguna hanya tinggal memilih nama tanah yang akan dinilai dan aplikasi akan memberikan hasil alternatif dari tanah yang telah dipilih tersebut. Tahapan implementasi yang dilakukan untuk menyelesaikan perancangan aplikasi penilaian kesehatan tanah pada tanaman jagung ini diperlukan informasi mengenai penyediaan perangkat keras (Hardware) dan perangkat lunak (Software).

Berikut disediakan perangkat keras dan perangkat lunak yang dibutuhkan.

\section{Spesifikasi Perangkat Keras}

Aplikasi penilaian kesehatan tanah pada tanaman jagung ini, telah diuji pada smartphone dengan spesifikasi perangkat keras sebagai berikut:
1. Prosessor : Intel Core i3 4030U 1.9 Ghz

2. Harddisk space : $500 \mathrm{~Gb}$

3. Memory RAM : $4.00 \mathrm{~Gb}$

4. VGA Card Onboard

5. Monitor LCD 11 Inch

6. Optical Mouse

7. Keyboard

\section{Spesifikasi Perangkat Lunak}

Aplikasi ini dijalankan pada perangkat lunak dengan spesifikasi sebagai berikut:

1. Sistem Operasi : Microsoft Windows 10 32 bit

2. Database XAMPP, PhpMyAdmin.

3. Visual Studio.Net 2012

\section{Tampilan Aplikasi Penilaian Kesehatan Tanah}

Tampilan aplikasi penilaian kesehatan tanah pada tanaman jagung ini terdiri dari tampilan menu utama, penilaian, data tanah dan tentang. Adapun tampilan menu-menu aplikasi penilaian kesehatan tanah pada tanaman jagung ini adalah sebagai berikut :

\section{Tampilan Menu Utama}

Tampilan menu utama terdiri dari penilaian, data tanah dan tentang.

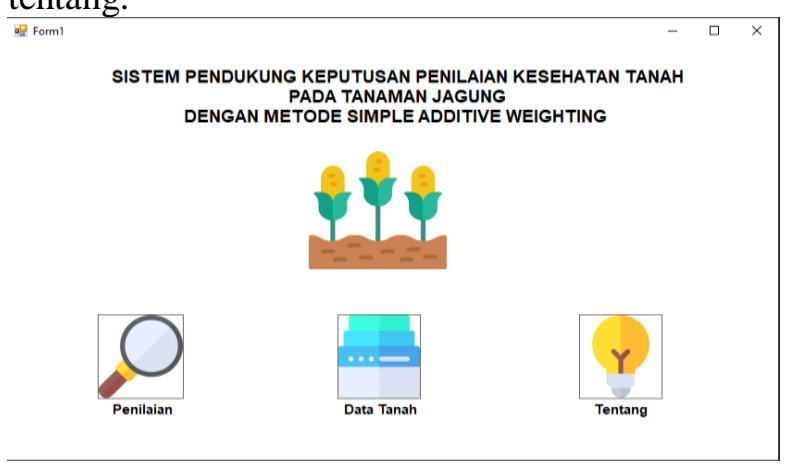

\section{Gambar Tampilan Menu Utama}

Berikut fungsi dari 3 tombol yang ada pada menu utama :

1. Tombol data tanah berfungsi untuk melakukan input data tanah yang akan dinilai. 
Available online at http://jurnal.goretanpena.com/index.php/JSSR

2. Penilaian berfungsi untuk melakukan penilaian terhadap tanah yang dipilih.

3. Tombol tentang berfungsi untuk melihat profil pembuat aplikasi penilaian kesehatan tanah pada tanaman jagung.

\section{Tampilan Penilaian}

Tampilan penilaian berfungsi untuk melakukan penilaian terhadap nama tanah yang telah dipilih untuk mendapatkan alternatif tanah yang baik digunakan.

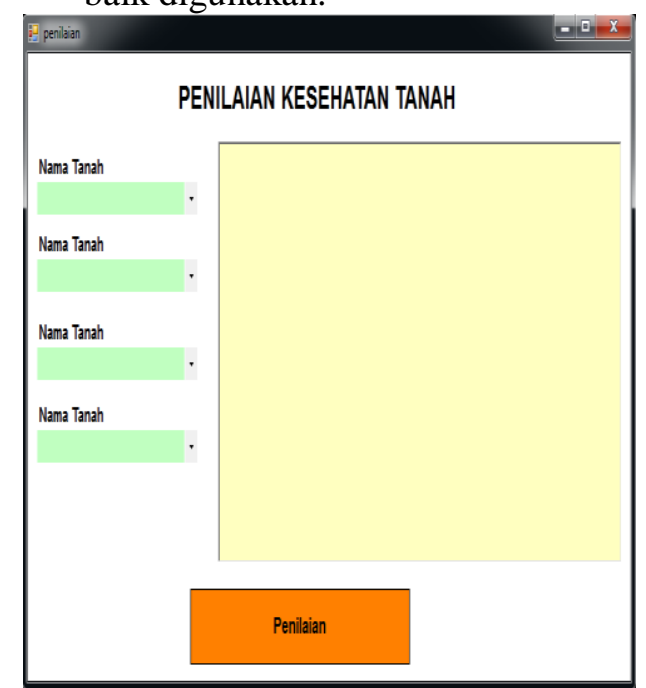

Gambar Tampilan Penilaian

\section{Tampilan Data Tanah}

Tampilan data tanah berfungsi untuk melakukan input data tanah yang akan dinilai dengan aplikasi.

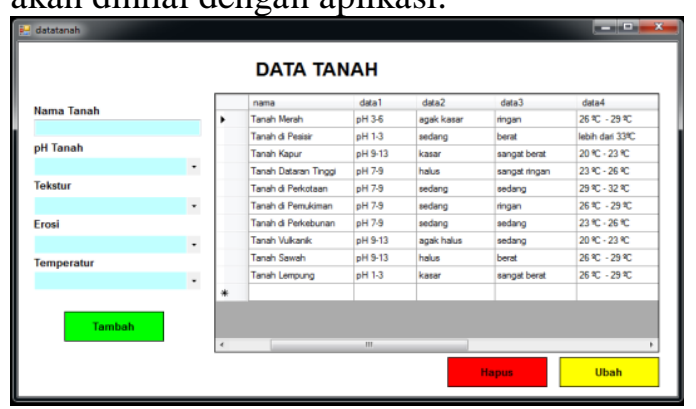

Gambar Tampilan Data Tanah

\section{Tampilan Tentang}

Tampilan tentang berfungsi untuk melihat profil pembuat aplikasi penilaian kesehatan tanah pada tanaman jagung.

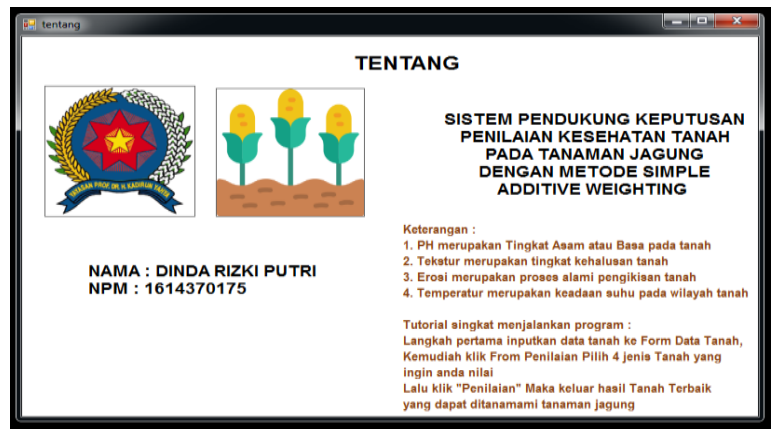

\section{Gambar Tampilan Tentang}

\section{Pengujian Aplikasi Penilaian}

\section{Kesehatan Tanah}

Pengujian aplikasi penilaian kesehatan tanah pada tanaman jagung ini digunakan untuk menguji sistem pada salah satu menu dimana data yang digunakan adalah proses melakukan konsultasi terhadap tanaman kacang tanah. Cara menggunakan aplikasi penilaian kesehatan tanah pada tanaman jagung adalah sebagai berikut :

1. Langkah awalnya user menjalankan aplikasi dan akan tampil menu utama.

SISTEM PENDUKUNG KEPUTUSAN PENILAIAN KESEHATAN TANAH PADA TANAMAN JAGUNG DENGAN METODE SIMPLE ADDITIVE WEIGHTING
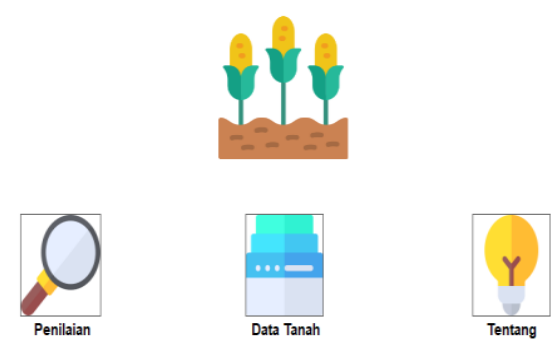

\section{Gambar Login}

2. Kemudian user melakukan klik pada tombol penilaian untuk melakukan seleksi tanah yang akan dipilih.

3. Setelah masuk, pengguna dapat langsung memilih nama tanah yang akan diseleksi tersebut dan kemudian klik pada tombol penilaian yang berada dibawah. 
Available online at http://jurnal.goretanpena.com/index.php/JSSR

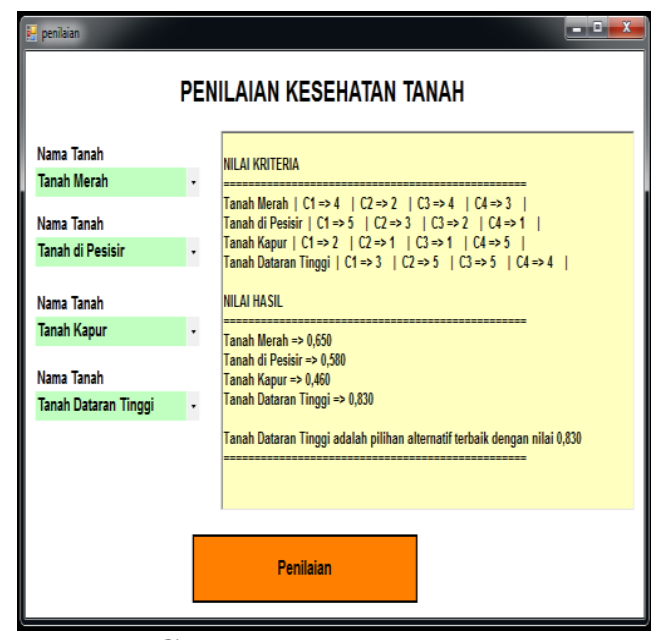

Gambar Menu Utama

4. Hasil akhir yang akan diberikan user adalah nama tanah yang baik diantara nama tanah yang dipilih. Nama tanah dengan nilai tertinggi adalah alternatif terbaik yang dapat dipilih untuk menanam jagung.

5. Inilah foto tanaman jagung dan tanah terbaik.

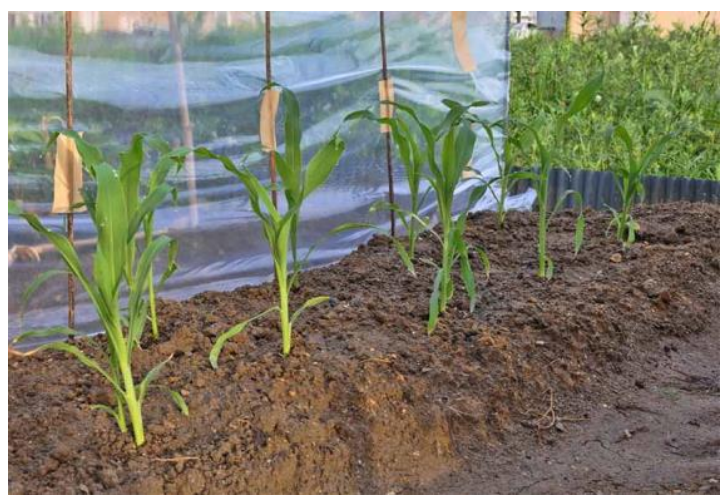

Gambar Foto Tanah

\section{SIMPULAN}

Dalam aplikasi yang telah dibuat ini menggunakan metode simple additive weighting untuk melakukan seleksi penilaian pada beberapa tanah untuk mendapatkan kesimpulan tanah mana yang terbaik untuk tanaman jagung berdasarkan kriteria pada tanah tersebut.

Beberapa faktor yang digunakan untuk melakukan seleksi tanah ini adalah dengan $\mathrm{PH}$ tanah, tekstur, erosi dan temperatur agar dapat dilakukan seleksi tanah mana yang terbaik untuk tanaman jagung.

\section{DAFTAR PUSTAKA}

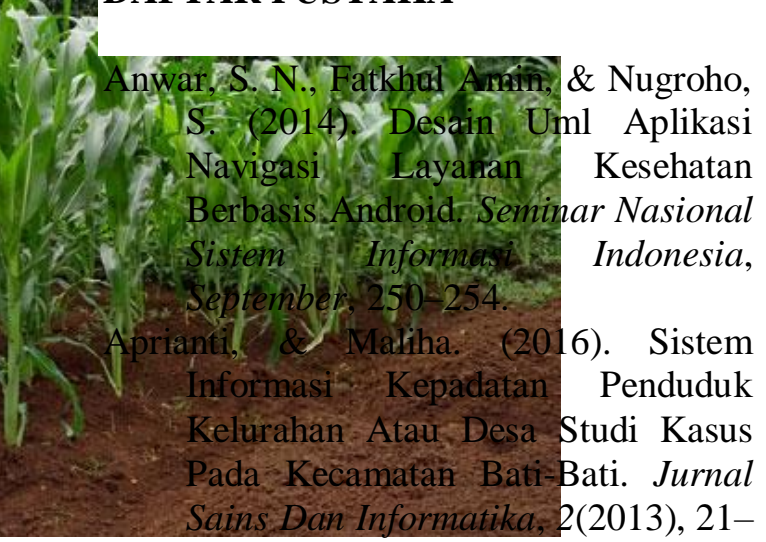
28.

Arifin, M., Putri, N., Sandrawati, A., \& Harryanto, R. (2018). Pengaruh Posisi Lereng terhadap Sifat Fisika dan Kimia Tanah pada Inceptisols di Jatinango. Soilrens, 16(2), 37-44.

Bhato, M. A. (2016). Respon Pertumbuhan dan Hasil Jagung (Zea 
Available online at http://jurnal.goretanpena.com/index.php/JSSR

mays L.) Varietas Pioner terhadap Berbagai Takaran Pupuk Kandang Babi dan Jarak Tanam. Jurnal Pertanian Konservasi Lahan Kering, 1(02), 85-89.

Ermatita. (2016). Analisis Dan Perancangan Sistem Informasi Perpustakaan. Jurnal Sistem Informasi, 8(1), 966-977.

Frieyadi. (2016). Dalam Sistem Pendukung Keputusan Promosi. Metode Yang Digunakan Dalam Menentukan Promosi Promosi Ini Simple Additive Weight (SAW). Jurnal Pilar Nusa Mandiri, 1, 3745.

Harumy, T.H.F., Julham Sitorus, M. L. (2018). Sistem Informasi Absensi Pada Pt . Cospar Sentosa Jaya Menggunakan Bahasa Pemprograman Java. Jurnal Teknik Informartika, 5(1), 63-70.

Haviluddin. (2011). Memahami Penggunaan UML ( Unified Modelling Language ). Jurnal Informatika Mulawarman, 6(1), 115.

Juarti. (2016). Analisis Indeks Kualitas Tanah Andisol Pada Berbagai Penggunaan Lahan Di Desa Sumber Brantas Kota Batu. Jurnal Pendidikan Geografi, 2, 58-71.

Kurniawan, T. A. (2018). Pemodelan Use Case (UML): Evaluasi Terhadap beberapa Kesalahan dalam Praktik. Jurnal Teknologi Informasi Dan Ilmu Komputer, 5(1), 77. https://doi.org/10.25126/jtiik.201851 610

Lars, \& Snell, M. (2016). Microsoft $₫$ Visual Studio ${ }^{\circledR} 2015$ Unleashed. Pearson Education, Inc.

Parmadi, A. (2019). Pemetaan Zona Nilai Tanah Menggunakan Metode Analitical Heirarchy Process (AHP). $1-26$.

Raharjo, J. S. D., Damiyana, D., \& Hidayatullah, M. (2016). Sistem Pakar Diagnosa Penyakit Lambung dengan Metode Forward Chaining
Berbasis Android. Sisfotek Global, 6(2), 1-8.

Rani, S. (2014). Sistem Pendukung Keputusan Pemilihan Sepeda Motor Berbasis Web Denga Metode Weighted Product. Pelita Informatika Budi Darma, 7(3), 6266.

Salelua, S. A., \& Maryam, S. (2018). Potensi Dan Prospek Pengembangan Produksi Jagung (Zea Mays L.) Di Kota Samarinda (Potency and Prospect of Corn Production Development (Zea mays L.) in Samarinda City). Jurnal Agribisnis Dan Komunikasi Pertanian (Journal of Agribusiness and Agricultural Communication), 1(1), 47.

Saputra, D., \& Elisabet. (1386). Sistem Pendukung Keputusan Pemilihan Kondisi Tanah Terbaik Untuk Perkebunan Di Desa Keputran Dengan Metode Ahp. 09, 283.

Saragih, A., Rosinta, E., \& Jhoni, S. (2015). Perancangan Aplikasi ELibrary Menggunakan Bahasa Pemrograman PHP Pada Universitas Methodist Indonesia. Jurnal TIMES, IV (1), 31-35.

Suprayitno, U. I. W. (2012). Pembangunan Sistem Stok Barang Dan Penjualan Pada Toko Sero Elektronik. Indonesian Jurnal on Computer Science Speed, 4(4), 816.

Suryasari, Callista, A., \& Sari, J. (2012). Rancangan Aplikasi Customer Service Pada PT. Lancar Makmur Bersama. Jurnal Sistem Informasi (JSI), 4(2), 468-476.

Urva, G., \& Siregar, H. F. (2015). Pemodelan UML E- Marketing Minyak Goreng. 9, 92-101.

Wahyudin, A., Ruminta, R., \& Nursaripah, S. A. (2017). Pertumbuhan dan hasil tanaman jagung (Zea mays L.) toleran herbisida akibat pemberian berbagai dosis herbisida kalium glifosat. Jurnal Kultivasi, 15(2), 86-91. 
Available online at http://jurnal.goretanpena.com/index.php/JSSR

Widyati, E. (2013). Pentingnya Keragaman Fungsional Organisme Tanah Terhadap Produktivitas Lahan. Tekno Hutan Tanaman, 6(1), 29-37.

Yulansari, K., \& Sukandi. (2013). Sistem Informasi Pengelolahan Data Iuran Badan Pembantu Penyelenggaraan Pendidikan Sekolah Menengah
Kejujuran Negri 2 Donorojo. Seminar Riset Unggulan Nasional Informatika Dan Komputer FTI UNSA 2013, 2(1), 5-13. 